\title{
A sensitivity analysis of the effect of pumping parameters on hydraulic fracture networks and local stresses during Shale Gas operations
}

\author{
Rachel F. Westwood ${ }^{\text {ab }}$, Samuel M. Toon ${ }^{\mathrm{a}}$ and Nigel J. Cassidy ${ }^{\mathrm{ac}}$ \\ ${ }^{a}$ School of Geography, Geology and the Environment, Keele University, Keele, Staffordshire ST5 5BG \\ ${ }^{\mathrm{b}}$ Present address: Learning and Professional Development Centre, Keele University, Keele, Staffordshire \\ ST5 5BG \\ ${ }^{c}$ Present address: School of Engineering, University of Birmingham, Edgbaston, Birmingham B15 2TT \\ Emails: r.f.westwood@keele.ac.uk (Rachel Westwood); s.m.toon@keele.ac.uk (Samuel Toon); \\ n.j.cassidy@bham.ac.uk (Nigel Cassidy) \\ Corresponding Author: Rachel F. Westwood
}

\begin{abstract}
The shale gas industry has significant impact on economies around the world, however, it is not without risk. One of the primary concerns is felt seismicity and recent earthquakes, caused by fault reactivation related to hydraulic fracturing operations, have escalated uncertainty about hydraulic fracturing methods. Mitigating these risks is essential for restoring public confidence in this controversial industry. We investigate the effect that changing two operational parameters (flow rate and pumping time) and differential pressure has on the flow distance, fracture network area and the minimum lateral distance that hydraulic fracturing should occur from a pre-existing fault in order not to reactivate it (lateral respect distance); thus reducing the risk of felt seismicity. Sensitivity analyses are conducted using a Monte Carlo approach. The lateral respect distance is obtained from calculations of the Coulomb stress change of the rock surrounding the injection stage, for four stress threshold values obtained from the literature. Results show that the flow rate has the smallest rate of change for fracture area $\left(3700 \mathrm{~m}^{2}\right.$ per $\left.0.01 \mathrm{~m}^{3} / \mathrm{s}\right)$ and flow distance $\left(8.3 \mathrm{~m}\right.$ per $\left.0.01 \mathrm{~m}^{3} / \mathrm{s}\right)$. We find that differential pressure has the largest impact on stimulated fracture area, when less than $2 \mathrm{MPa}$, at $31,029 \mathrm{~m}^{2} / \mathrm{MPa}$. The pumping time has the most significant effect on the flow distance $(48 \mathrm{~m} / \mathrm{hr}$ ) and the stress threshold value the most significant effect on the lateral respect distance. This study suggests that to reduce the lateral distance, a compromise is required between flow distance and fracture area. The results obtained by this research provide invaluable guidance for operational practice in determining the potential area of the induced fracture network and generated stress field under realistic hydraulic fracturing conditions, an important aspect for risk assessments.
\end{abstract}

Keywords: Hydraulic fracturing; Numerical Modelling; Pumping Parameters; Stress; Shale Gas; Faulting 


\section{Introduction}

Hydraulic fracturing for shale gas is a controversial energy option and not without risks. In the UK alone, the Shale Gas economy is estimated to be valued at four billion pounds per year [1], but there are significant concerns about the environmental impact on its development within a national context [2]. Felt seismicity is one of the primary concerns and in April-May 2011, public anxiety increased as hydraulic fracturing of the UK's first well for shale gas exploration, near Blackpool in Lancashire, caused two felt earthquakes $\left(\mathrm{M}_{\mathrm{L}} 2.3\right.$ and 1.5) [3,4]. Just prior to this, felt seismic events due to hydraulic fracturing operations had also been experienced in the Eola Field in Oklahoma, USA [5] and the Horn River Basin in British Columbia, Canada [6]. Later, in 2013, hydraulic fracturing operations caused felt seismicity in Doe-Dawson, British Columbia, Canada [7] and Ohio, USA, where there have been a number of 'unusual' events [8,9]. More recently, Crooked Lake in Alberta, Canada has experience a sequence of 160 events [10]. Events greater than M4.0 have been observed near Fox Creek, Alberta $[11,12]$ and Fort St James in British Columbia [13].

There have been a number of events in Ohio, Arkansas and Oklahoma, associated to shale gas operations, but which were a consequence of re-injection of wastewater [14,15]. Hundreds of thousands of shale gas hydraulic fracturing episodes have occurred without issue; however, it is these few instances of felt seismicity that the public remembers. It is, therefore, essential that the risks and uncertainty are fully understood and minimized in order to restore public confidence in the exploration and exploitation of shale gas and hydraulic fracturing. This is particularly the case in the UK, where permission has recently been granted for a number of exploratory wells.

The detection of the minimum resolvable fault displacement can depend on a number of factors. However, current 2D seismic reflection technology has detected faults in coal mining with a throw as small as 4-5 $\mathrm{m}$ [16]. This allows operators to evaluate the surrounding geology and assess the current stress state, location, size and criticality of any weaknesses and the possibility of these slipping when a change in stress is applied. The magnitude of any induced event that occurs along a fault can be estimated using Kanamori and Anderson's [17] relationship between magnitude and fault size, constrained by slip length. The maximum magnitude of events normally associated with hydraulic fracturing would have a rupture length of less than a few hundred metres and a slip of only millimetres [18].

The process of hydraulic fracturing creates a network of new induced fractures and reactivated dilated preexisting natural fractures. Fractures propagate in the plane containing the maximum and intermediate stresses By analysing data of microseismic event clouds from thousands of hydraulic stimulations, two papers have agreed that the vertical extent at which hydraulic fractures extend is less than $600 \mathrm{~m}$ from the well perforation [20,21]. An initial numerical modelling study to examine the lateral distance of the Coulomb stress change from hydraulic fracturing operations and the effect that this may have on preexisting faults was presented in Westwood et al. [19]. The study adopted a Monte Carlo approach and showed that it is the failure threshold that has the most significant impact on the horizontal respect distance (the minimum lateral distance that hydraulic fracturing should occur from a pre-existing fault in order not to reactivate it), with values ranging from $63 \mathrm{~m}$ to $433 \mathrm{~m}$ depending on the combination of fracture intensity and failure threshold. Vasuvedan and Eaton [22] demonstrated that Coulomb stress analysis could be applied to hydraulic fracturing using a source mechanism of a combination of strike-slip and reverse movement. The modelling work of Rutqvist et al. [23] found that shear and tensile failure occur simultaneously and that, when a fault is present, events are larger than the small microseismic events generated by the hydraulic fracturing process. Yoon et al. [24] modelled the response of a 
geothermal reservoir, using Discrete Element Modelling, to fluid injection and found that cyclic pumping rather than a constant pump rate decreased the occurrence of induced seismicity.

Sensitivity studies have investigated whether the total fracture volume, aperture, and porosity are sensitive to the fracture length [25] and the effect that cohesion, the in situ-stress ratio, the internal friction angle [26] and injection rate [26,27] have on the natural fractures. It was found that the total fracture volume, aperture, and porosity are not sensitive to the fracture length. The injection rate impacts on fracture complexity, with an increased rate increasing the stimulated fracture area [26] and fracture length [27]. Cohesion, internal friction angle and the in situ-stress ratio all affect the morphology of the fracture network, with fractures orientated toward the maximum stress direction enhancing the fracture network complexity [26]. All of these results were based on one Discrete Fracture Network (DFN), rather than applying a Monte Carlo approach.

In this paper we investigate some of the issues that were not addressed by previous analyses and focus on the application of operational-related parameters (such as flow rate) that have direct relevance to realworld Shale Gas operation across the globe. We conduct sensitivity analyses by applying a Monte Carlo approach that, investigates, the effect that pumping time and differential pressure at injection have on 1) fracture area, 2) maximum flow distance and, 3) the lateral respect distance that hydraulic fracturing should occur from a fault in order that it is not reactivated. In addition, we also apply the same method to investigate the effect that the flow (or injection) rate has on these three parameters. The model and these methods are described in Section 2, whilst in Section 3, we present the results and discuss the effect and implications of them in Section 4, before providing concluding remarks in Section 5.

\section{Methods}

We apply the numerical modelling approach described by Westwood et al. [19], which uses Golder Associates' Fracman 7.5 software to generate discrete fracture networks (DFN) to model natural, and induced fracturing in a 3D geological volume. Hydraulic fracture simulations are run on the DFN to obtain a network of opened natural and newly created hydraulic fractures. The DFN, geological, fracture

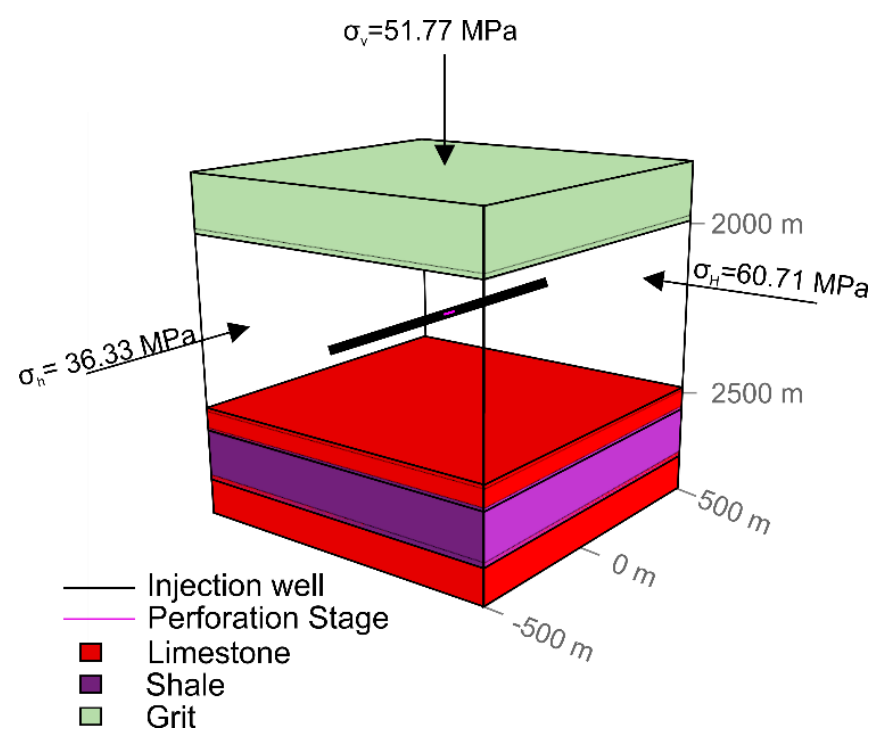

Fig. 1. The model used for generating the discrete fracture network, including the geological stratigraphy, stresses and well geometry (see key). The transparent block, which the well passes through, is also shale. The fracking perforation stage is located in the centre of the injection well at a depth of $2220 \mathrm{~m}$. 


\begin{tabular}{|c|c|c|}
\hline DFN Paran & & \\
\hline Enhanced $\mathrm{F}$ & er Model & \\
\hline Fracture siz & wer law distribution & \\
\hline Aperture: 1 & & \\
\hline Permeabilit & $01 \mathrm{mD}$ & \\
\hline Compressil & $10^{-6} \mathrm{~Pa}^{-1}$ & \\
\hline Fracture or & on distribution: Fisher & \\
\hline Fractures: 1 & pole trend: 80 & \\
\hline Fractures: 1 & pole plunge: 0 & \\
\hline Fracture int & $: \mathrm{P} 32=0.15$ & \\
\hline Geology $\mathrm{Pa}$ & & \\
\hline Shale & Young's modulus (GPa) & 42.5 \\
\hline & Poisson ratio & 0.25 \\
\hline Limestone & Young's modulus (GPa) & 70 \\
\hline & Poisson ratio & 0.22 \\
\hline Grit & Young's modulus (GPa) & 22.6 \\
\hline & Poisson ratio & 0.24 \\
\hline Fracture $\mathrm{Pa}$ & & \\
\hline Coefficient & ction: 0.47 & \\
\hline Cohesion: 5 & $\mathrm{~Pa}$ & \\
\hline Stresses & & \\
\hline$\sigma_{\mathrm{H}}: \quad 60.71$ & & \\
\hline$\sigma_{\mathrm{v}}: \quad 51.77$ & & \\
\hline$\sigma_{\mathrm{h}}: \quad 36.33$ & & \\
\hline
\end{tabular}

Tab. 1. The properties used for creating the model and discrete fracture network.

and stress parameters used in the model are provided in Tab. 1 and the model design is shown in Fig. 1. The elastic properties are homogeneous across the layer. The model is based on the geology at Preese Hall, near Blackpool, in the northwest of England, UK. The stresses are based on those published for the Bowland and Worston Shale formations [28]. The shales lie at a depth between $1957 \mathrm{~m}$ and $2690 \mathrm{~m}$, with a $60 \mathrm{~m}$ layer of limestone sandwiched between them, with its top at $2479 \mathrm{~m}$. Above the Bowland shale formation lies Millstone Grit and below the Worston shale, the Clitheroe limestone complex (Tab. 2).

The exact fracture intensity in this region is unknown, therefore we use a fracture intensity based on the findings of Westwood et al. [19], with a P32 (area of fractures per unit volume) of 0.15 , the value which generated the largest lateral respect distance of the three values used by Westwood et al. [14]. The stress regime is defined to be strike-slip. The values of $\sigma_{\mathrm{H}}, \sigma_{\mathrm{h}}$ and $\sigma_{\mathrm{v}}$ are obtained from those derived in the reports commissioned by Cuadrilla following hydraulic fracturing at Preese Hall [28,29,30,31]. Young's modulus is calculated from the shear and bulk modulus derived in [31] and is slightly higher than some of the shales of North America [19]. The value for Poisson's ratio is comparable to the Barnett shale [32].

Three sets of parameters are considered and calculated for a range of values. These are: 


\begin{tabular}{|c|lll|}
\hline \multicolumn{2}{|l}{ STRATIGRAPHY } & Top TVD $(\mathrm{m})$ & Top MD $(\mathrm{m})$ \\
\hline \multirow{3}{*}{ Triassic } & Sherwood Sandstone Group & 194.37 & 207 \\
\cline { 2 - 4 } & St Bees Sandstone & 410.7 & 424 \\
\hline \multirow{3}{*}{ Permian } & Manchester Marl & 1016.96 & 1030 \\
\cline { 2 - 4 } & Collyhurst Sandstone & 1157.1 & 1109 \\
\hline \multirow{5}{*}{ Carboniferous } & Lower Coal Measures & 1233.25 & 1247 \\
\cline { 2 - 4 } & Millstone Grit Group & 1266.03 & 1280 \\
\cline { 2 - 4 } & Bowland Shale formation & 1956.7 & 1993 \\
\cline { 2 - 4 } & Pendlestone Limestone & 2478.9 & 2507 \\
\cline { 2 - 4 } & Worston Shale formation & 2540.85 & 2576 \\
\cline { 2 - 4 } & Clitheroe Limestone Complex & 2689.61 & 2744 \\
\hline
\end{tabular}

Tab. 2. The stratigraphy at Preese Hall, near Blackpool, UK. Data from [22].

1. Differential pressure (dP). This is "the pressure difference between pore pressure and normal pressure on the fractures at injection" [33]. A parametric study is performed every $1.5 \mathrm{MPa}$ from $0.676 \mathrm{MPa}$ (equivalent to an instantaneous shut-in pressure (ISIP) of $37.5 \mathrm{MPa}$ at Preese Hall) to 11.176 MPa (ISIP = 48 MPa at Preese Hall). This was further refined to every $0.25 \mathrm{MPa}$ between $0.676 \mathrm{MPa}$ and $2.926 \mathrm{MPa}$. This range was selected from the ISIP values obtained at the Preese Hall well from minifrac and formation integrity tests (FIT) [30].

For all simulations:

- flow rate $=0.117 \mathrm{~m}^{3} / \mathrm{s}$

- pump time $=100 \mathrm{mins}$

This gives a total of $702 \mathrm{~m}^{3}$ of injected water.

2. Flow Rate. This is the rate at which fluid is injected into the well. The parametric study is performed every $1000 \mathrm{~m}^{3} / \mathrm{d}\left(0.012 \mathrm{~m}^{3} / \mathrm{s}\right)$ between $8500 \mathrm{~m}^{3} / \mathrm{d}\left(0.09 \mathrm{~m}^{3} / \mathrm{s}\right)$ and $16,500 \mathrm{~m}^{3} / \mathrm{d}(0.19$ $\left.\mathrm{m}^{3} / \mathrm{s}\right)$ inclusive. Previous numerical modelling has used injection rates of $1717 \mathrm{~m}^{3} / \mathrm{d}\left(0.02 \mathrm{~m}^{3} / \mathrm{s}\right)$ to $17,170 \mathrm{~m}^{3} / \mathrm{d}\left(0.2 \mathrm{~m}^{3} / \mathrm{s}\right)[23,27]$. These correspond with the injected rates used in the Upper Cotton Valley Formation of $1832 \mathrm{~m}^{3} / \mathrm{d}\left(0.0212 \mathrm{~m}^{3} / \mathrm{s}\right)$ to $2290 \mathrm{~m}^{3} / \mathrm{d}\left(0.0265 \mathrm{~m}^{3} / \mathrm{s}\right)$ [34]. We extend the lower bound of this range to $0.012 \mathrm{~m}^{3} / \mathrm{s}$ which is the typical value used during Stage 2 of the Preese Hall hydraulic fracturing (Cuadrilla, pers comm).

For all simulations:

- Differential pressure $=0.926 \mathrm{MPa}$ (equivalent to an ISIP of $37.75 \mathrm{MPa}$ at Preese Hall)

- pump time $=100$ mins

The total amount of fluid injected ranges from $540 \mathrm{~m}^{3}$ to $1140 \mathrm{~m}^{3}$.

3. Pumping Time. This is the length of time that the fluid is pumped into the well. The parametric study is performed every 30 mins from 30 mins to 360 mins. Previous modelling has used pump times of one hour [27], two hours [19] and three hours [23].

For all simulations:

- Differential pressure $=0.926 \mathrm{MPa}$ (equivalent to an ISIP of $37.75 \mathrm{MPa}$ at Preese Hall)

- Flow rate $=0.117 \mathrm{~m}^{3} / \mathrm{s}$.

The total amount of fluid injected ranges from $210.6 \mathrm{~m}^{3}$ to $1140 \mathrm{~m}^{3}$.

A Monte Carlo approach using fifty fracture set realisations for each scenario is applied to obtain a statistical representation of the results. In addition to analysing the data generated by Fracman, the new 
and opened natural fractures are imported into Matlab for Coulomb Stress Analysis. The algorithms described by Okada [35] are used to calculate failure on optimally oriented strike-slip faults (faults whose orientation is optimal for failure in a strike-slip regime), by performing the calculations at each point of a $50 \mathrm{~m}$ discretized $2 \mathrm{~km} \times 2 \mathrm{~km} \times 2 \mathrm{~km}$ cube. For a source mechanism that contains $40 \%$ inflation and $60 \%$ strike-slip, the calculation involves multiply the inflation component of Okada's [35] model by 0.4 and the strike-slip component by 0.6 and summing the resultant stresses.

A stress map is obtained by calculating the maximum and minimum stresses over depth at each point. Three weighted source mechanisms are evaluated:

- Source mechanism 1: $50 \%$ inflation, 25\% strike-slip, 25\% reverse

- Source mechanism 2: $25 \%$ inflation, 50\% strike-slip, $25 \%$ reverse

- Source mechanism 3: 25\% inflation, 25\% strike-slip, 50\% reverse

Triggering a critical fault is not modelled explicitly, instead the lateral distance is calculated using four stress threshold values: 0.001 MPa, 0.1 MPa, 0.3 MPa, and 0.5 MPa. These were selected on the basis of published threshold values in studies of fault movement and triggering. Freed [36] uses aftershock studies to define triggering at $0.1 \mathrm{MPa}$ to $0.3 \mathrm{MPa}$ or less. Kilb et al. [37] state that the optimal triggering threshold is $0.1 \mathrm{MPa}$, but find correlations with seismicity rate change for value between $0.001 \mathrm{MPa}$ and $0.5 \mathrm{MPa}$. The results of Shapiro et al. [38] also indicate that triggering occurs as low as $0.001-0.1 \mathrm{MPa}$. As this is quite a wide range, we perform the lateral distance calculation on the upper and lower values of each of these ranges.

\section{Results}

The following subsections present the results looking at 1) the total fracture area; 2) the maximum flow distance and; 3) the lateral respect distance.

\subsection{Fracture area}

Fig. 2 presents the results of the three studies related to the fracture area. The average fracture area decreases as the differential pressure $(\mathrm{dP})$ increase and has a bimodal relationship, split at $2 \mathrm{MPa}$. The $\mathrm{dP}$ has more effect on the average fracture area at values less than $2 \mathrm{MPa}$. Above $2 \mathrm{MPa}$, the rate of change is $2530 \mathrm{~m}^{2} / \mathrm{MPa}$, whereas, below $2 \mathrm{MPa}$, it is over twelve times greater, at $31,029 \mathrm{~m}^{2} / \mathrm{MPa}$.

The fracture area increases linearly as the pump time and flow rate increase, at a rate of $400 \mathrm{~m}^{2} / \mathrm{min}$ and $37,000 \mathrm{~m}^{2}$ per $0.1 \mathrm{~m}^{3} / \mathrm{s}$ respectively. The pumping time gives the largest range of fracture area values, with the maximum area calculated being $187,585 \mathrm{~m}^{2}$ when pumping for 360 mins and the smallest being just $21,800 \mathrm{~m}^{2}$ when pumping for only 30 mins. The flow rate gives a much smaller range of $31,815 \mathrm{~m}^{2}$.

\subsection{Maximum flow distance}


Fig. 3 presents the results of the three studies related to the maximum flow distance. The solid line in the top graph of Fig. 3 shows that the average maximum flow distance decreases as $\mathrm{dP}$ increases, following a bimodal relationship, split at $4 \mathrm{MPa}$. Below $4 \mathrm{MPa}$ the distance decreases at a rate of $45 \mathrm{~m} / \mathrm{MPa}$, reducing to just $5 \mathrm{~m} / \mathrm{MPa}$ above $4 \mathrm{MPa}$.

The average maximum flow distance increases at a rate of $83 \mathrm{~m}$ per $0.1 \mathrm{~m}^{3} / \mathrm{s}$ flow rate. For these simulations, the minimum value is relatively constant, fluctuating by $+/-30 \mathrm{~m}$ around $250 \mathrm{~m}$; however,
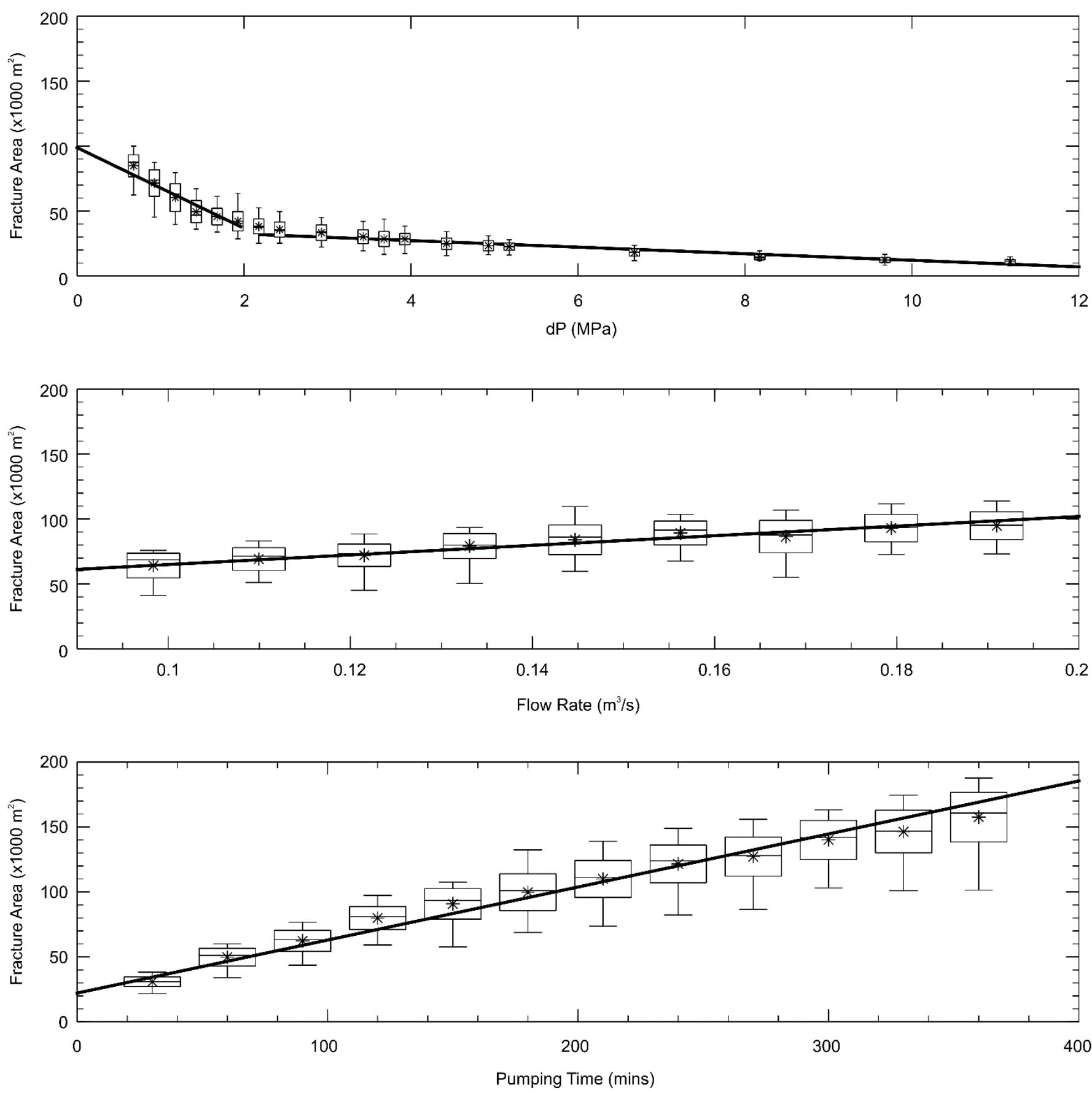

Fig. 2. Results for fracture area. These show the effect on fracture area for a range of values of differential pressure, flow rate and pump time. The simulation for each parameter is run 50 times. The tails indicate the maximum and minimum values of the data set, the box ends are the mean plus/minus 1 standard deviation, the star is the mean and the horizontal line the median. 
the maximum values have a greater range, with at least one simulation for $0.145 \mathrm{~m}^{3} / \mathrm{s}$ and $0.168 \mathrm{~m}^{3} / \mathrm{s}$ reaching $620 \mathrm{~m}$. The pumping time gives the largest range of values, from $160 \mathrm{~m}$ pumping for $30 \mathrm{mins}$ to one result of $780 \mathrm{~m}$ when pumping for 330 mins. The average maximum flow distance increases as the pumping time increases at a rate of $0.8 \mathrm{~m} / \mathrm{min}$.
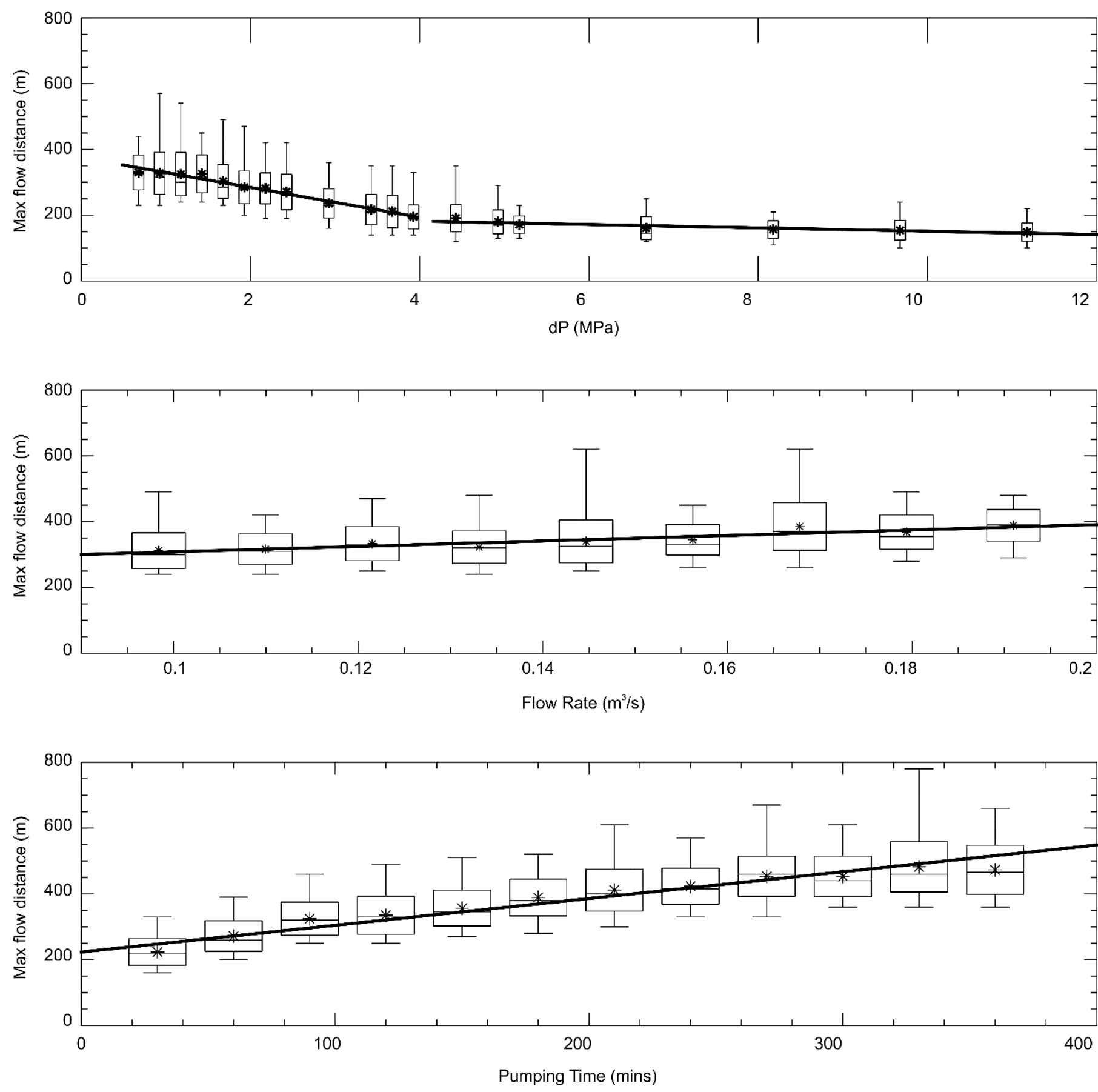

Fig. 3. Results for the maximum flow distance. These show the effect on the maximum flow distance for a range of values of differential pressure, flow rate and pump time. The simulation for each parameter is run 50 times. The tails indicate the maximum and minimum values of the data set, the box ends are the mean plus/minus 1 standard deviation, the star is the mean and the horizontal line the median. 


\subsection{Lateral respect distance}

Two-dimensional Coulomb failure stress maps using source mechanism 2 are presented in Fig. 4. The columns show the results based on the $\mathrm{dP}$, flow rate and pump time simulations respectively and the rows are the results for the three parameter values, detailed next to the arrow at the top of the respective column. The distance at which the stress reaches $0.00001 \mathrm{MPa}$ (the outer contours) decreases as $\mathrm{dP}$ increases, remains near constant as flow rate increases and increases as pump time increases.

The radiation pattern is very similar across the rows and columns, showing that changing the source mechanism does vary the radiation pattern slightly, although not significantly (Fig. 5). Similarly, the extent of the amplitude of the stress is not affected greatly by the weighting of the source mechanism. The areas where failure could occur are the areas of positive Coulomb stress, highlighted by the solid black contour lines in Fig. 4 and Fig. 5, although, for failure to occur in this region, it is dependent on the amount of stress required to trigger movement. The concept of the amount of stress required to trigger a critical fault is discussed widely in the literature. We use the same three sources as in [19] to examine the effect that four threshold values (0.001MPa [37,38], 0.1 MPa [36,37,38], 0.3 MPa [36] and 0.5 MPa [37]) have on the lateral respect distance. Fig. 6 shows the results of the average lateral distance for the four failure thresholds (columns), the three parameter sets (rows) and the three weighted source mechanisms. The most obvious result is that the lateral respect distance is higher for all three rows for the $0.001 \mathrm{MPa}$ threshold value by

- $125 \mathrm{~m}$ at the shortest pump time and $200 \mathrm{~m}$ at the longest pump time

- $150 \mathrm{~m}$ at the lowest flow rate and $175 \mathrm{~m}$ at the highest flow rate

- $210 \mathrm{~m}$ at the lowest $\mathrm{dP}$ and $75-100 \mathrm{~m}$ at the highest $\mathrm{dP}$.

The lateral respect distances for the $0.1 \mathrm{MPa}, 0.3 \mathrm{MPa}$ and $0.5 \mathrm{MPa}$ thresholds vary by less than $25 \mathrm{~m}$. The maximum average distance is $263 \mathrm{~m}$ for $0.001 \mathrm{MPa}$ with a $\mathrm{dP}$ of $0.676 \mathrm{MPa}$ (flow rate $=0.117 \mathrm{~m}^{3} / \mathrm{s}$; pump time $=100$ mins) and $267 \mathrm{~m}$ for a pump time of $360 \mathrm{mins}$ (flow rate $=0.117 \mathrm{~m}^{3} / \mathrm{s} ; \mathrm{dP}=0.926 \mathrm{MPa}$ ). The average of the lateral distance for each pumping parameter, for source mechanism 2 , is provided in the graphs in Fig. 6. Interestingly, all the stress thresholds display a negative 0.2 power law relationship between the lateral respect distance for source mechanism 2 and the $\mathrm{dP}$. Also, the gradient of the pumping time ( $p$ in $\mathrm{m}$ per $\mathrm{min}$ ) and the gradient of the flow rate $\left(f\right.$ in $\mathrm{m}$ per $0.01 \mathrm{~m}^{3} / \mathrm{s}$ ) are related by:

$$
f=10 p+0.1 .
$$



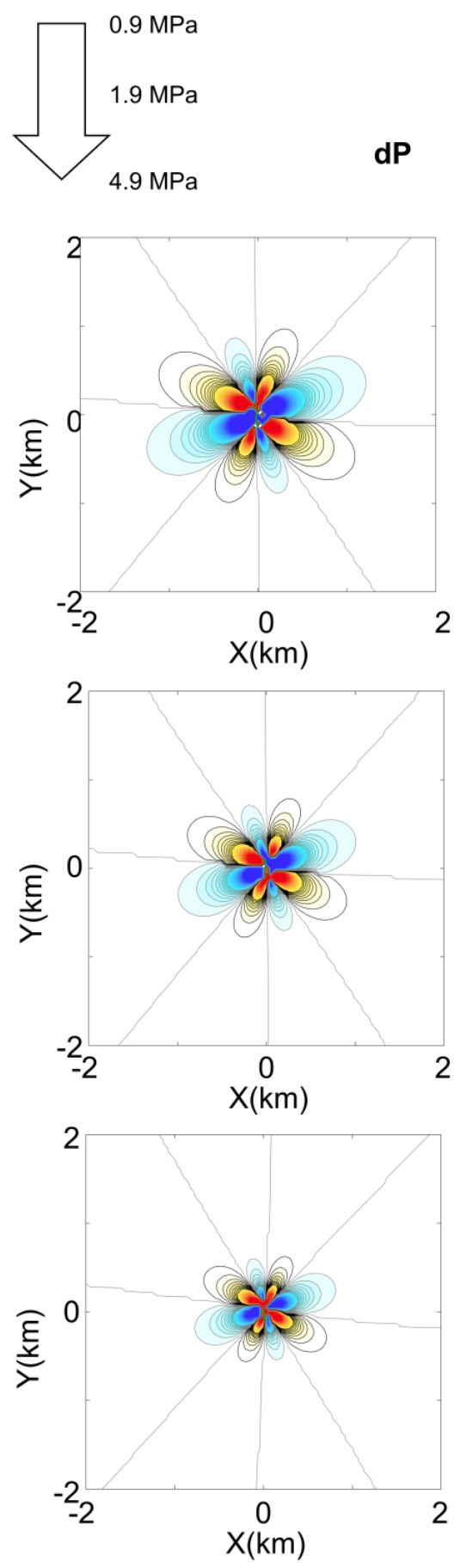

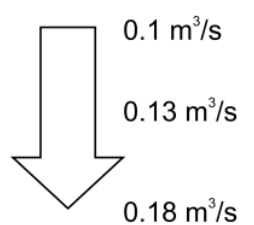

Flow Rate
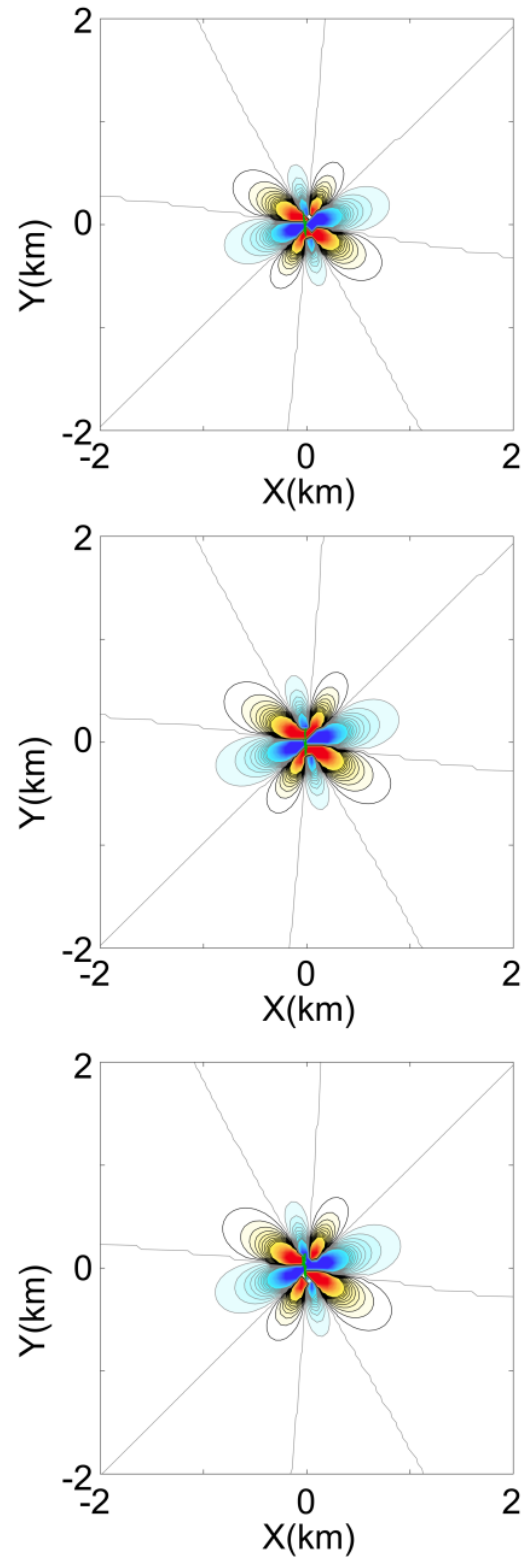

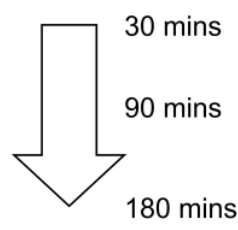

Pump Time
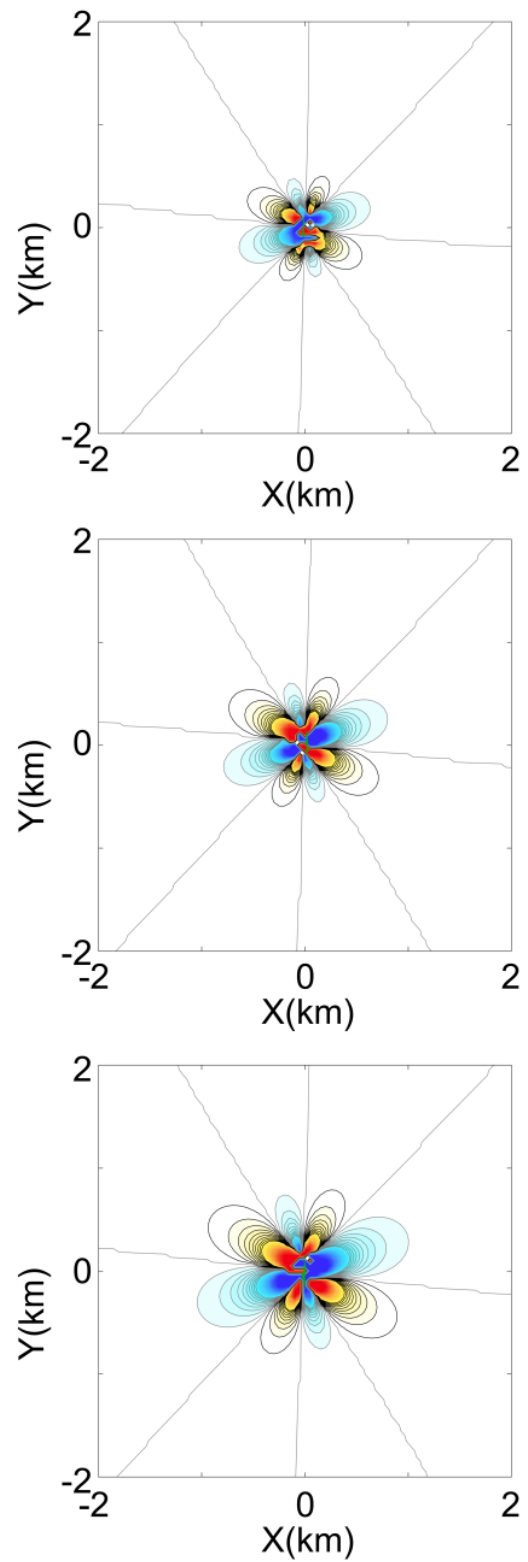

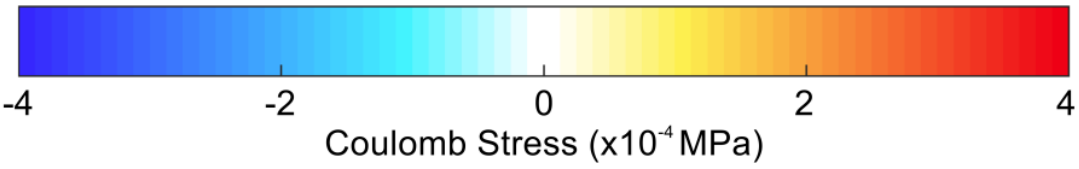

Fig. 4. Coulomb failure stress maps for a $25 \%$ inflation, $50 \%$ strike-slip, $25 \%$ reverse (source mechanism 2) stress regime. The columns show the three different parameters that the parametric modelling sweep are conducted over. The value used for each calculation is indicated by the arrow at the top of the column. Calculations were carried out at $50 \mathrm{~m}$ intervals on a $4 \mathrm{~km} \times 4 \mathrm{~km} \times 2 \mathrm{~km}$ grid. The maximum and minimum stresses are calculated depth-wise and indicated by the solid and dashed lines respectively at $0.00001 \mathrm{MPa}$ intervals. 


\section{Source mechanism weightings}
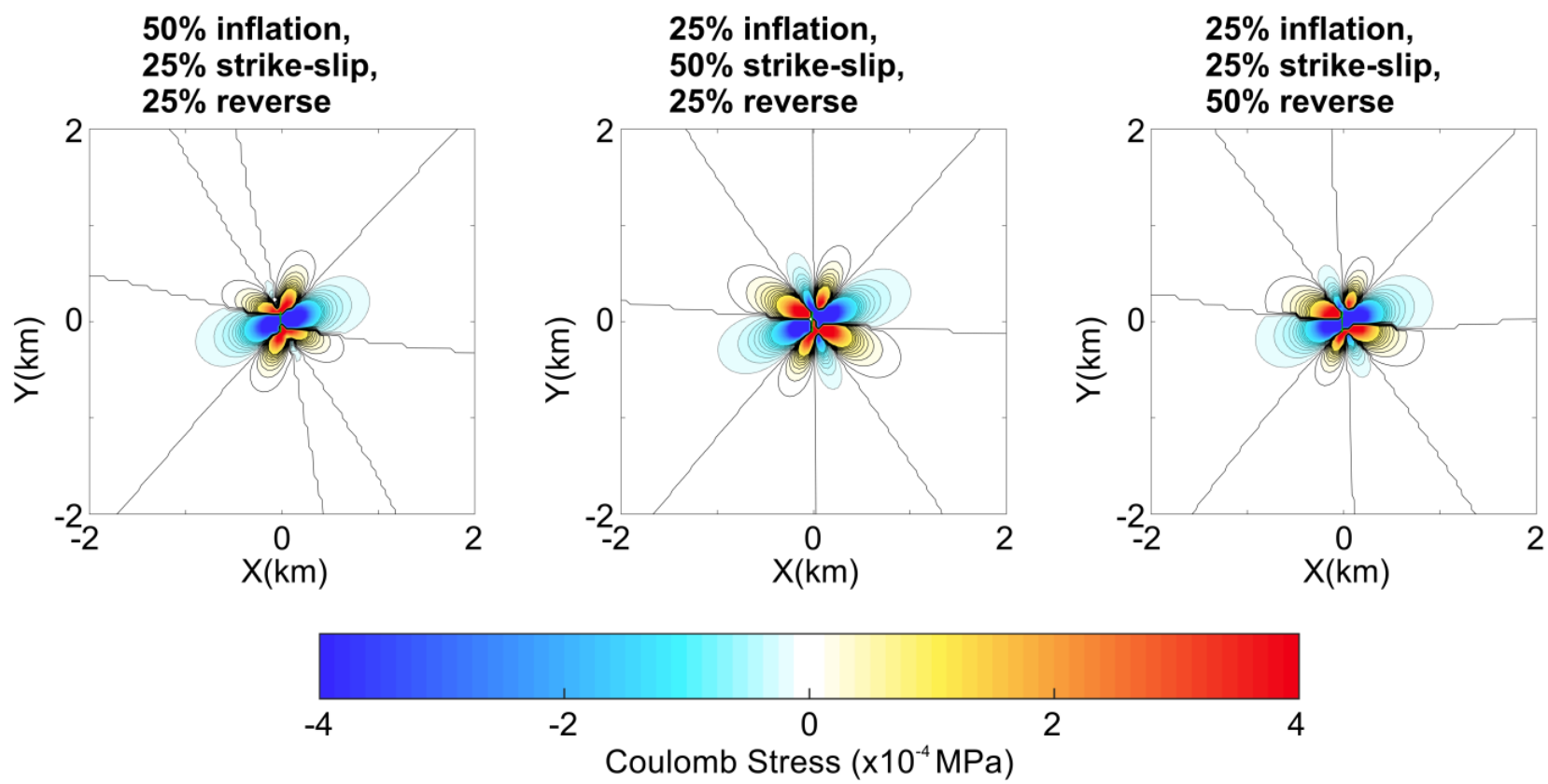

Fig. 5. Stress maps for three different source weightings. The calculation uses $\mathrm{dP}=1.926 \mathrm{MPa}$, pump time $=100$ mins and flow rate $=0.12 \mathrm{~m}^{3} / \mathrm{s}$. Calculations were carried out at $50 \mathrm{~m}$ intervals on a $4 \mathrm{~km} \times 4 \mathrm{~km} \times 2 \mathrm{~km}$ grid. The maximum and minimum stresses are calculated depth-wise and indicated by the solid and dashed lines respectively at $0.00001 \mathrm{MPa}$ intervals. 

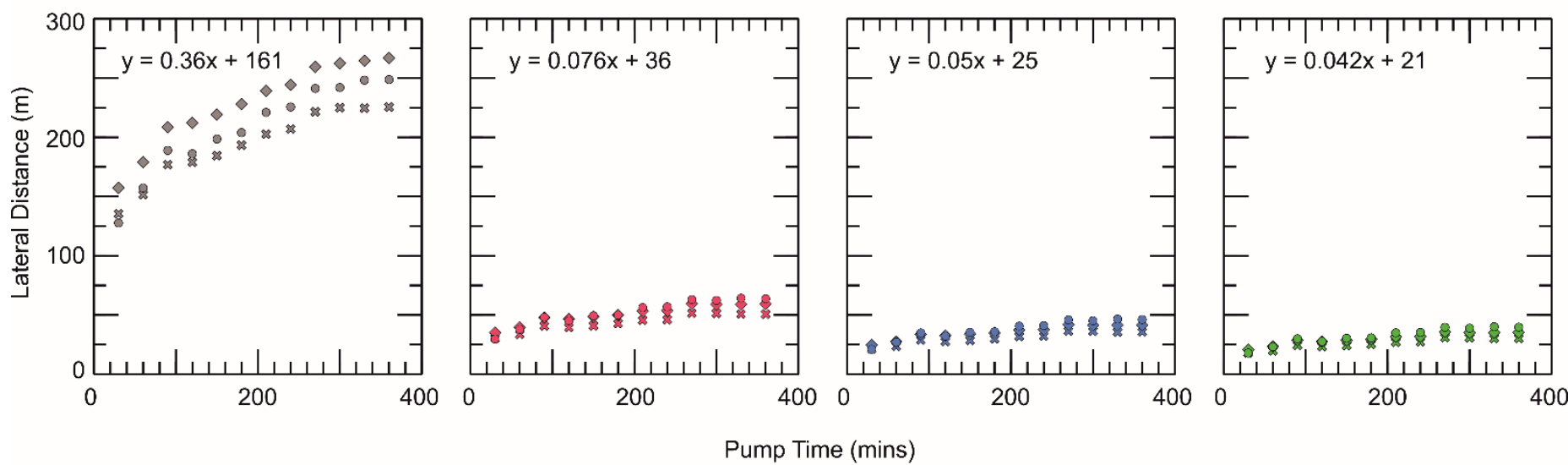

Pump Time (mins)
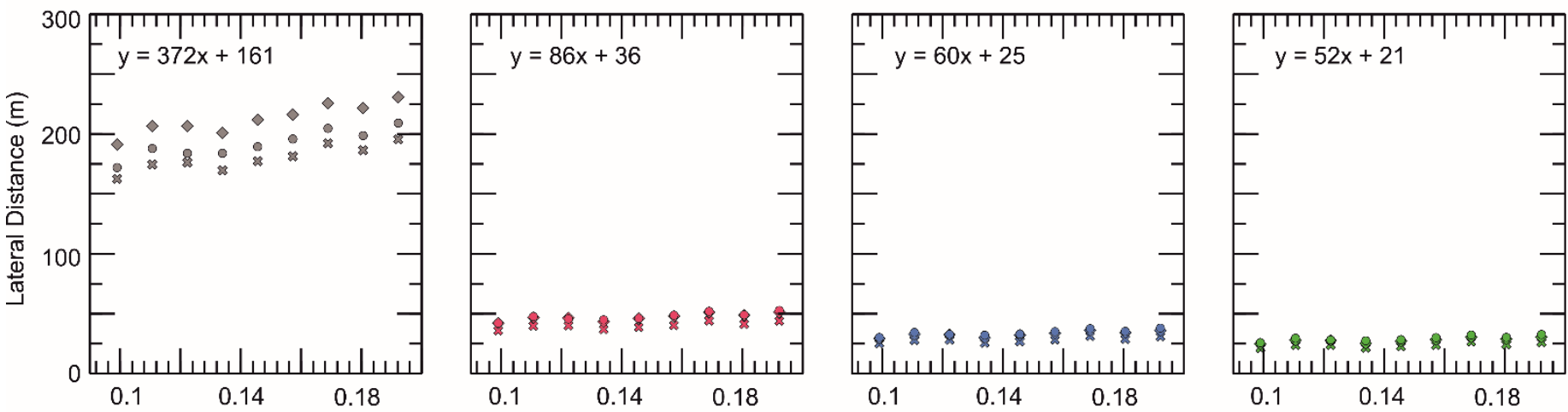

Flow Rate $\left(\mathrm{m}^{3} / \mathrm{s}\right)$
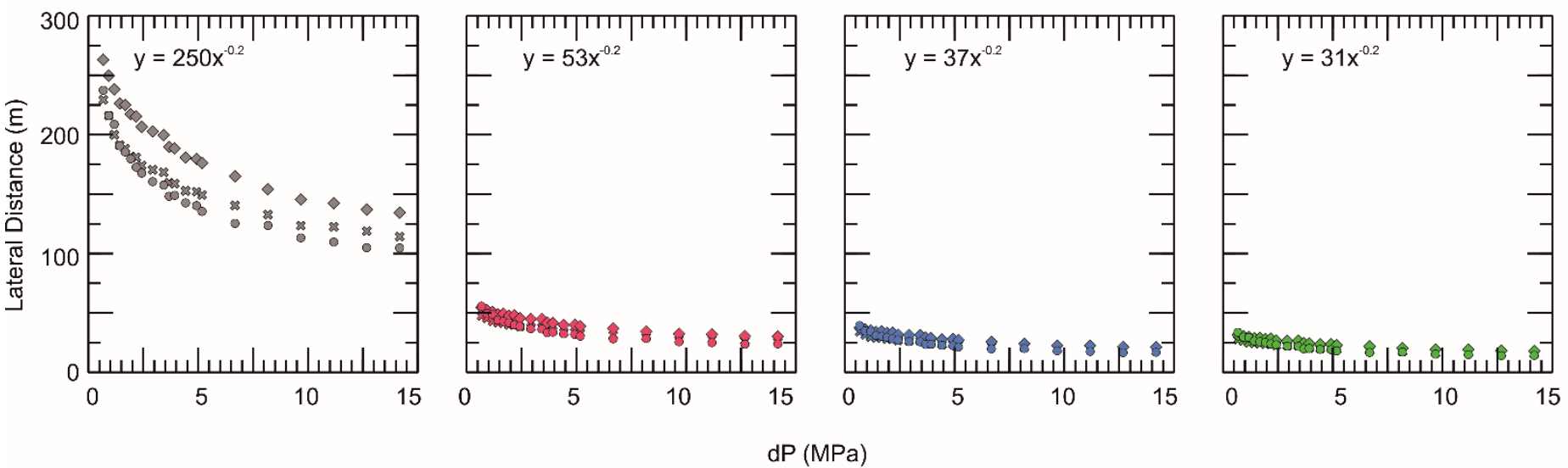

$\mathrm{dP}(\mathrm{MPa})$

Source mechanism 1: $50 \%$ inflation, $25 \%$ strike-slip, $25 \%$ reverse

$\diamond$ Source mechanism 2: $25 \%$ inflation, $50 \%$ strike-slip, $25 \%$ reverse

§ Source mechanism 3: $25 \%$ inflation, $25 \%$ strike-slip, $50 \%$ reverse

Fig. 6. The average lateral distances for each set of 50 simulations over the parameter ranges for pump time (top row), flow rate (middle row) and differential pressure (bottom row). Calculations were performed for three weighted source mechanisms. The columns show the results relating to each stress threshold value: 0.001 MPa [30,31], 0.1 $\mathrm{MPa}$ [30,31,29], 0.3 $\mathrm{MPa}$ [29] and 0.5 $\mathrm{MPa}$ [30]. The equations provide the relationship between the respective parameter and the lateral respect distance for source mechanism 2 . 


\subsection{Assessing thresholds for operational parameters}

A final set of simulations were performed using a subset of parameters discussed in the previous sections that relate to a potential 'worst case', with respect to the lateral respect distance and 'best (or worst) case' with respect to flow distance, depending on the desires of the operator ('best case' if the operator requires a large flow distance, knowing the geology and 'worst case' if that distance interacts with pre-existing faults, creating possible contamination pathways). Differential pressure, flow rate and pump time were selected where the lateral respect distance and maximum flow distance were largest. This model was generated with $\mathrm{dP}=0.676 \mathrm{MPa}$, pump time $=360 \mathrm{mins}$ and a flow rate $=0.19 \mathrm{~m}^{3} / \mathrm{s}$. The calculations for the lateral respect distance were carried out for all three of the source mechanisms discussed previously and it was found that source mechanism 2 gave marginally larger results than the other two source mechanisms.

Using source mechanism 2, the results give an average lateral distance of $300 \mathrm{~m}$, an average flow distance of $462 \mathrm{~m}$ and an average fracture area of $148,351 \mathrm{~m}^{2}$. The maximum lateral distance was $600 \mathrm{~m}$, the maximum flow distance $700 \mathrm{~m}$ and the maximum fracture area $169,430 \mathrm{~m}^{2}$.

\section{Discussion}

This paper investigates the effect on fracture area, flow distance and the lateral respect distance when changing the pump time, differential pressure $(\mathrm{dP})$ at injection and flow (injection) rate. Previous sensitivity studies have considered the effect on fracture volume, aperture and porosity when changing fracture length [25]; the effect on complexity of the fracture network when altering cohesion, the in-situ stress ratio, internal friction angle and injection rate $[26,27]$ and the effect on the lateral respect distance (the lateral distance from a known fault that hydraulic fracturing should occur in order not to reactivate the fault) for different fracture intensities [19]. This paper adds to these investigations. The results presented in this paper are of particular interest to shale gas operators, researchers and regulators. We have shown how changing one parameter by a small amount can increase the distance of flow and induced fracture area. Similarly, one small change can reduce the risk of a seismic event occurring on a preexisting critical fault.

The operational parameters considered in this paper are all practical, hydraulic fracturing parameters that can be directly controlled during shale gas operations. We find that the flow rate has limited effect on all of the output variables. This contradicts the findings of Wang et al. [26] who state that the injection rate has a "crucial role" in determining the fracture network complexity and the stimulation area. However, their models were based on an experiment conducted at the surface. This means that their values for the regional stresses $\left(\sigma_{\mathrm{H}}\right.$ and $\left.\sigma_{\mathrm{v}}\right)$ were not realistic of those found at the depths of shale and were over 1500 and 1100 times smaller, respectively, than the values obtained for Preese Hall and used in this paper. The work by Wang et al. was also conducted on a much smaller scale, over an area of $400 \mathrm{~mm}$ x $400 \mathrm{~mm}$, with injection rates $10^{-7}$ times smaller than used during shale gas operations. Abaa et al. [27] also looked at injection rate, but considered the effect on propped fracture length rather than flow distance. However, for the same $0.1 \mathrm{~m}^{3} / \mathrm{s}$ to $0.2 \mathrm{~m}^{3} / \mathrm{s}$ range $(\sim 60-100 \mathrm{bpm})$ their results are near constant. At lower injection values $(\leq 40 \mathrm{bpm})$ the fracture length is considerably shorter. Flow rates this low $\left(\leq 0.08 \mathrm{~m}^{3} / \mathrm{s}\right)$ were not considered in this paper as they do not represent typical injection rates used during operation. Our results show that flow rate has the least effect on fracture area, flow distance and the lateral respect distance, with rates of change of only $3700 \mathrm{~m}^{2}$ per $0.01 \mathrm{~m}^{3} / \mathrm{s}, 8.3 \mathrm{~m}$ per $0.01 \mathrm{~m}^{3} / \mathrm{s}$ and $3.72 \mathrm{~m}$ per $0.01 \mathrm{~m}^{3} / \mathrm{s} \mathrm{respectively}$, 
indicating that there is significant operational flexibility in the flow rates that can be applied on site without being concerned about affecting key fracture-related conditions.

At values of $\mathrm{dP}$ below $2 \mathrm{MPa}$, the effect on fracture area is greater than that produced by changing the injection rate or pumping time. When $\mathrm{dP}$ is above $2 \mathrm{MPa}$, the effect is minimal and pumping time has the greatest effect. Pumping time affects both fracture area and flow distance. At dP values below $4 \mathrm{MPa}$, pumping time and $\mathrm{dP}$ have a comparable effect on flow distance $(48 \mathrm{~m} / \mathrm{hr}$ and $45 \mathrm{~m} / \mathrm{MPA}$ respectively), which are significantly greater than the effect of flow rate $\left(8.3 \mathrm{~m}\right.$ per $\left.0.01 \mathrm{~m}^{3} / \mathrm{s}\right)$. In practise $\mathrm{dP}$ and flow rate are linked, although $\mathrm{dP}$ is not an operational parameter it can be controlled by altering the flow rate. This is an important consideration when assessing fracture stage pressures and the impact they will have on nature, area and extent of the induced fracture network. The lateral extent of the stress field also decreases as $\mathrm{dP}$ increases which has implications for potential fault reactivation and the likelihood of unintentionally generating new fracture-controlled fluid pathways.

The lateral respect distance is also affected by pumping time although the greatest factor affecting lateral distance is the stress threshold. The maximum average distance is $267 \mathrm{~m}$ at a threshold of $0.001 \mathrm{MPa}$, pumping for 360 mins. The minimum average distance is $14 \mathrm{~m}$ at a threshold of $0.5 \mathrm{MPa}$ and $\mathrm{dP}$ of 12.676 $\mathrm{MPa}$. The maximum distance obtained over all simulations was $523 \mathrm{~m}$ (threshold $=0.001 \mathrm{MPa}$, pump time $=360$ mins, source mechanism 2). The range of values predicted in this research provide invaluable guidance for operational practice as they help to determine the potential distance from the hydraulic fracturing stage that stress changes could occur due to hydraulic fracturing operations under realistic conditions, an important aspect of any operational risk-based assessment.

Interestingly, the source mechanism weighting produces very similar shaped stress maps for each combination. The direction of fracture growth is visible from the stress maps, which is in the direction of the maximum horizontal stress. Although source mechanism 2 produced slightly higher average lateral distances for the 0.001 MPa threshold than the other two weightings, it does not exceed $45 \mathrm{~m}$ (Fig. 7). However, should pumping go on for longer than 360 mins, the difference between source mechanism 2 and 3 is likely to increase and become more evident, which may help constrain maximum pumping times on site. This small difference in the stress maps between the weightings agrees with the findings of Vasudevan \& Eaton [22]. These results are positive and highly significant for operational practice as it means that regardless of the source mechanism, operators can define a safe lateral respect distance for hydraulic fracturing operations away from known faults and other structural weaknesses.

Based on the results, it would be expected that to maximise the flow distance through the natural fractures, a low $\mathrm{dP}$ should be used, combined with a long pumping time. Increasing the pumping time from 100 mins to 360 mins ( 3.5 times increase) and decreasing the $\mathrm{dP}$ to $0.676 \mathrm{MPa}$, increased the average fracture area over 1.5 times from $95,000 \mathrm{~m}^{2}$ to $148,350 \mathrm{~m}^{2}$ and both the lateral respect distance, for the $0.001 \mathrm{MPa}$ threshold, and the average flow distance by over $70 \mathrm{~m}$. However, reducing the $\mathrm{dP}$ from $0.926 \mathrm{MPa}$ to $0.676 \mathrm{MPa}$ and increasing the flow rate to $0.19 \mathrm{~m} / \mathrm{s}$, had no significant effect on the average flow distance or fracture area; the average lateral distance for the $0.001 \mathrm{MPa}$ threshold increased by only $32 \mathrm{~m}$. This indicates that the parameter with the largest effect on flow distance and fracture area is the pumping time.

The methods presented in this research can be applied to other industries, like geothermal energy, which use hydraulic fracturing, as well as to other shale gas reservoirs by changing the geological parameters. We acknowledge that this research is limited by the fact that is based on the geology of a specific area, Preese Hall in the UK. Extending the research to investigate further geological scenarios is a topic of 


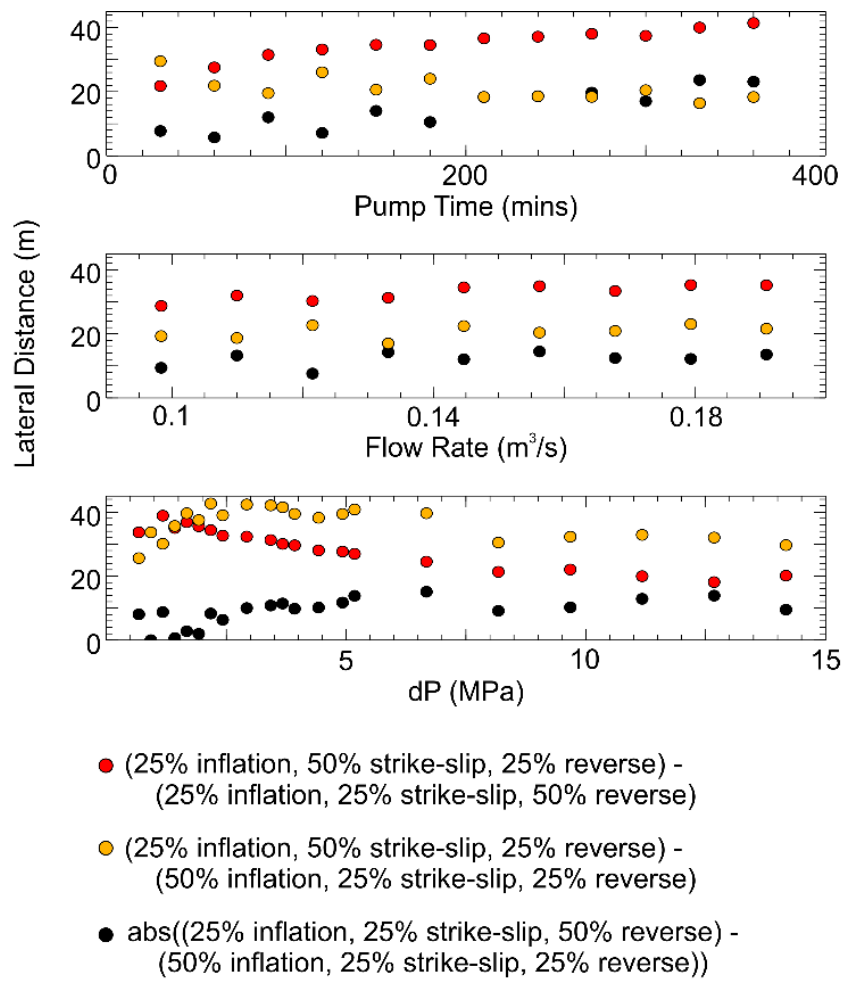

Fig. 7. The difference in the average lateral respect distance between weighting mechanisms using the $0.001 \mathrm{MPa}$ threshold.

further work. Additionally, further work will investigate the effect that different hydraulic fracturing fluid compositions have on the flow distance and fracture area.

\section{Conclusions}

In this paper we have numerically modelled the effect that the operational parameters of flow rate, pump time and differential pressure at injection have on the lateral respect distance, fracture area and the maximum flow distance, as defined by the operational and geological conditions at the UK's first Shale gas site at Preese Hall in Lancashire. A sensitivity analysis was performed using a range of values for each of the above:

- $\quad$ dP: 0.676:1.5:11.176 MPa and 0.676:0.25:2.926 MPa;

- flow rate: 8500:1000:16500 m³/d;

- $\quad$ pump time: 30:30:360 minutes.

Using the discrete fracture network based Fracman modelling software, we applied a Monte Carlo approach to our analysis, generating fifty unique discrete fracture networks for each parameter value in the ranges. Coulomb stress analysis was performed in Matlab software to investigate the lateral respect distance, the horizontal distance that hydraulic fracturing should occur from a fault in order for it not to be reactivated. Using a $2 \mathrm{~km} \times 2 \mathrm{~km} \times 2 \mathrm{~km}$ cube, discretised into $50 \mathrm{~m}$ sections, the maximum and minimum stresses over depth were obtained for three weighted source mechanisms and visualised as stress maps. The lateral respect distance was calculated using four threshold values obtained from literature. 
We have shown that that if the $\mathrm{dP}$ is kept below $2 \mathrm{MPa}$ and flow rate at a sensible value, then the flow distance and fracture area can be controlled using the pumping time, but this will increase the lateral respect distance. To reduce the lateral respect distance, there has to be a trade-off with the flow distance and fracture area. Therefore, it is important that operators know the geology and locations of faults prior to hydraulic fracturing, so that this judgement can be made with full and sound knowledge.

\section{Acknowledgements}

This work was supported by SHEER (Shale gas Exploration and Exploitation Induced Risks), which has received funding from the European Union's Horizon 2020 research and innovation programme under grant agreement No 640896. We would like to thank Cuadrilla Resources Ltd for providing geomechanical parameters, and Mark Cottrell and Gareth Digges La Touche at Golder Associates (UK) Ltd for their support with Fracman. Thanks also goes to Dr Jamie Pringle for his valued advice and to the reviewers for their constructive comments which have helped to improve the paper. 


\section{References}

[1] Taylor C. Getting shale gas working. Institute of Directors; 2013. Report No.: Infrasture for Business 2013 \#6.

[2] Economic Affairs Committee. The Economic Impact on UK Energy Policy of Shale Gas and Oil. London: The House of Lords; 2014. Report No.: HL Paper 172.

[3] Galloway DD. Bulletin of British Earthquakes 2011. Internal Report. Edinburgh: British Geological Survey; 2012. Report No.: OR/12/041.

[4] Clarke H, Eisner L, Styles P, Turner P. Felt seismicity associated with shale gas hydraulic fracturing: The first documented example in Europe. Geophys Res Lett 2014;41(23): 83088314. DOI: $10.1002 / 2014$ GL062047.

[5] Holland AA. Earthquakes Triggered by Hydraulic Fracturing in South-Central Oklahoma. B Seismol Soc Am 2013;103(3): 1784-1792. DOI: 10.1785/0120120109.

[6] BC Oil and Gas Commission. Investigation of Observed Seismicity in the Horn River Basin. Technical Report. BC Oil and Gas Commission; 2012.

[7] BC Oil and Gas Commission. Investigation of Observed Seismicity in the Montney Trend. Technical report. BC Oil and Gas Commission; 2014.

[8] Friberg PA, Besana-Ostman GM, Dricker I. Characterization of an Earthquake Sequence Triggered by Hydraulic Fracturing in Harrison County, Ohio. Seismol Res Lett 2014;85(6): 1295-1307. DOI: 10.1785/0220140127.

[9] Skoumal RJ, Brudzinski MR, Currie BS. Earthquakes Induced by Hydraulic Fracturing in Poland Township, Ohio. Bulletin of the Seismological Society of America 2015;105(1): 189- 197, DOI: 10.1785/0120140168.

[10] Schultz R, Stern V, Novakovic M, Atkinson G, and Gu YJ. Hydraulic fracturing and the Crooked Lake sequences: Insights gleaned from regional seismic networks. Geophys. Res. Lett 2015, 42(18): 2750-8, DOI: 10.1002/2015GL063455

[11] Atkinson GM, Ghofrani H, and Assatourians K. Impact of induced seismicity on the evaluation of seismic hazard: Some preliminary considerations. Seismol. Res. Lett 2015; 86(3): 1009-21: DOI: 10.1785/0220140204

[12] Bao X and Eaton DW, Fault activation by hydraulic fracturing in western Canada. Science 2016; 354: 1406-9: DOI: 10.1126/science.aag2583

[13] Atkinson G, Assatourians K, Cheadle B, and Greig W, "Ground motions from three recent earthquakes in Western Alberta and Northeastern British Columbia and their implications for induced-seismicity hazard in eastern regions," Seismol. Res. Lett. 2015 vol. 86(3): 102231: DOI: 10.1785/0220140195 
[14] Ellsworth WL. Injection-Induced Earthquakes. Science 2013;314(6142): 1225942.

[15] Kim WY. Induced Seicmicity Associated with Fluid Injection into a Deep Well in Youngstown, Ohio. Journal of Geophysical Research: Solid Earth 2013;118: 3506-3518. DOI: 10.1002/jgrb.50247.

[16] Zhou B, Hatherly P. Fault and dyke detectability in high resolution seismic surveys for coal: a view from numerical modelling. Exploration Geophysics 2013;45(3): 223-233. DOI: 10.1071/EG12082.

[17] Kanamori, K., Anderson, D. L. Theoretical Basis of Some Empirical Relations in Seismology. Bulletin of the Seismological Society of America. 1975; 65(5): 1073-1095

[18] Zoback MD, Gorelick SM. Earthquake triggering and large-scale geologic storage of carbon dioxide. Proc Natl Acad Sci USA 2012;109(26): 10164-10168. DOI: 10.1073/pnas.1202473109.

[19] Westwood R, Toon SM, Styles P, Cassidy N. Horizontal Respect Distance for Hydraulic Fracturing in the Vicinity of Faulting. Geomechanics and Geophysics for Geo-energy and Geo-resources. Under review;

[20] Davies RJ, Mathias SA, Moss J, Hustoft S, Newport L. Hydraulic fractures: How far can they go? Mar Petrol Geol 2012;37: 1-6. DOI: 10.1016/j.marpetgeo.2012.04.001.

[21] Flewelling SA, Tymchak MP, Warpinski N. Hydraulic fracture height limits and fault interactions in tight oil and gas formations. Geophys Res Lett 2013;40: 3602-3606. DOI: 10.1002/grl.50707.

[22] Vasudevan K, Eaton DW. Hydraulic fracturing: Coulomb failure stress in fracture networks. CSEG Recorder 2011;36(9): 24-31.

[23] Rutqvist J, Rinaldi AP, Cappa F, Moridis GJ. Modeling of fault activation and seismicity by injection directly into a fault zone associated with hydraulic fracturing of shale-gas reservoirs. J Petrol Sci Eng 2015;127: 377-386. DOI: 10.1016/j.petrol.2015.01.019.

[24] Yoon, JS, Zimmermann G, Zang A, Discrete element modeling of cyclic rate fluid injection at multiple locations in naturally fractured reservoirs. International Journal of Rock Mechanics \& Mining Sciences 2015; 74: 15-23. DOI: 10.1016/j.ijrmms.2014.12.003.

[25] Williams-Stroud S, Ozgen C, Billingsley RL. Microseismicity-constrained discrete fracture network models. Geophysics 2013;78(1): B37 - B47. DOI: 10.1190/GEO2011-0061.1.

[26] Wang Y, Li X, Zhang YX, Wu YS, Zheng B. Gas shale hydraulic fracturing: a numerical investigation of the fracturing network evolution in the Silurian Longmaxi formation in the southeast of Sichuan Basin, China, using a coupled FSD approach. Environ Earth Sci 2016;75(1093) DOI: 10.1007/s12665-016-5696-0. 
[27] Abaa K, Wang JY, Ityokumbul MT. Parametric study of fracture treatment parameters for ultra-tight gas reservoirs. J Petrol Explor Prod Technol 2013;3: 159-168. DOI:

10.1007/s13202-013-0058-x.

[28] de Pater CJ, Baisch S. Geomechanical Study of Bowland Shale. Synthesis Report. ; 2011.

[29] Baisch S, Vöros R. Geomechanical Study of Blackpool Seismicity. Q-con GmbH; 2011. Report No.: CUA001.

[30] GMI. Wellbore Failure Analysis and Geomechanical Modelling in the Bowland Shales, Blackpool, UK. Preliminary Technical Report. Baker Hughes Incorporated, Subsurface Integrity \& Evaluation; 2011.

[31] Harper TR. Well Preese Hall-1 The mechanism of Induced Seismicity. Geosphere Ltd; 2011.

[32] Dusseault MB. Geomechanical aspects of shale gas development. In Kwasniewski M, Lydzba D, editors. Rock Mechanics for Resources, Energy and Environment; 2013: CRC Press. p. 39-56.

[33] Golder Associates, "FracMan® User's Manual Release 7.5," 2015.

[34] Rutledge JT, Phillips WS, Mayerhofer MJ. Faulting Induced by Forced Fluid Injection and Fluid Flow Forced byFaulting: An Interpretation of Hydraulic-Fracture Microseismicity, Carthage Cotton Valley Gas Field, Texas. B Seismol Soc Am 2004;94(5): 1817-1830. DOI: $10.1785 / 012003257$.

[35] Okada Y. Internal deformation due to shear and tensile faults in a half-space. B Seismol Soc Am 1992;82(2): 1018-1040.

[36] Freed AM. Earthquake triggering by static, dynamic, and postseismic stress. Annu Rev Earth P1 Sc 2005;33: 335-367. DOI: 10.1146/annurev.earth.33.092203.122505.

[37] Kilb D, Gomberg J, Bodin P. Aftershock triggering by complete Coulomb stress. J Geophys Res-Sol Ea 2002;107(B4): ESE 2-1 - ESE 2-14. DOI: 10.1029/2001JB000202.

[38] Shapiro SA, Kummerow J, Dinske C, Asch G, Rothert E, Erzinger J, et al. Fluid induced seismicity guided by a continental fault: Injection experiment of 2004/2005 at the German deep drilling site (KTB). Geophys Res Lett 2006;33(1): L01309. DOI: 10.1029/2005GL024659. 